\title{
Four teleological theories of addiction
}

\author{
HOWARD RACHLIN \\ State University of New York, Stony Brook, New York
}

\begin{abstract}
Four theories are presented to account for addiction, defined as a high rate of consumption of a substance that is ultimately harmful to the organism. The theories are teleological and behavioral in the sense that the ultimate motivational forces they posit lie in the environmental context of behavior-in an economic utility function or a process of behavioral adjustment-rather than in an internal physiological or cognitive mechanism. A theory by the psychologists Richard Herrnstein and Drazen Prelec is discussed that shows how melioration (maximization of local, as opposed to overall, or global, utility) may lead down a "primrose path" to addiction. A theory by the economists Gary Becker and Kevin Murphy shows how a primrose path may exist even when overall utility is maximized-provided that utility of temporally distant events is discounted. Two other theories, one by George Stigler and Gary Becker and one introduced here, an elaboration of the Stigler-Becker theory called "relative addiction," specify economic properties of addictive substances that would create the primrose path.
\end{abstract}

Aristotle (Physics, book II, chapter 7) described motion of objects (including behavior of organisms) with two causal principles-efficient and final. ${ }^{1}$ Efficient causes, used predominantly in physics since the Renaissance, precede their effects (as the stimulus of a reflex precedes the response). Psychological explanation in terms of efficient causes specifies underlying mechanisms (neural circuitry or cognitive structure). Final causes, on the other hand, specify overlying patterns. The result of a final cause is not a response to a stimulus but a component of a pattern. An orchestra must play the first movement of a symphony, for example, in order to play the whole symphony-playing the symphony as a whole is the final cause of playing the first movement. Just as the effect of an efficient cause may be the cause of another effect (as in a chain of neural stimuli and responses), so the effect of a final cause may be the cause of another effect-playing the movement is the final cause of playing a theme within the movement. Teleological explanation is explanation in terms of final causes. When we say that the orchestra played the first movement because it was playing the symphony, or played the theme because it was playing the movement, we are providing a teleological explanation of behavior.

The utility functions of modern economics are final causes (Rachlin, 1992, 1994). A utility function is a pattern (mathematically expressed) into which particular behavioral observations fit. Behavior under a particular set of constraints (of budget and price) is assumed to maximize utility. Once a utility function is estimated in a given situation (with a given set of constraints), it may

The preparation of this manuscript was supported by grants from the National Institute of Mental Health and the National Institute of Drug Abuse. Correspondence should be addressed to H. Rachlin, Psychology Department, State University of New York, Stony Brook, NY 117942500 (e-mail: hrachlin@psychl.psy.sunysb.edu). be tested in other situations (with other constraints). If behavior, under the new constraints, fails to maximize the hypothesized utility function, the function is modified or a new function is hypothesized. Just as an organism's actions, as they are observed in many situations, may reveal an efficient cause-an underlying physiological or cognitive mechanism - so they may reveal a final cause-a utility function (Samuelson, 1937). Individual economics (microeconomics) is thus a teleological science and, since utility functions are supposed to have no existence other than as behavioral markers, it is also a behavioral science.

Because of their assumption that behavior maximizes utility, microeconomic theories are often called "rational" theories. (It would be irrational not to maximize utility.) But rationality in economics means merely that some utility function is maximized. Within economics there is no way to decide whether one utility function is more rational than another. For example, a person who chooses a penny today in preference to a million dollars tomorrow would be deemed rational by economic theory as long as that choice is consistent with (maximizes the same utility function as) the person's other choices. Rationality in economic theory, moreover, has nothing to do with consciousness. A rat that maximizes a utility function in choosing between laboratory chow, water, and electrical brain stimulation (Green \& Rachlin, 1991) is no less rational, according to economic theory, than a person choosing deliberately among items on a restaurant menu.

The economist Gary Becker and his colleagues (Becker, Grossman, \& Murphy, 1992; Becker \& Murphy, 1990; Stigler \& Becker, 1977) have proposed "rational" theories of addiction. And psychologists have demonstrated obedience to economic principles in the actual consumption of addictive substances by humans and other species (see articles in Green \& Kagel, 1996). This means only that addictive behavior may be explained in 
terms of maximization of some utility function-not necessarily that addicts are farsighted or that they themselves can provide coherent or convincing explanations for their behavior.

The four theories discussed here are of two kinds. Two are theories of how basic behavioral processes may result in excessive and harmful consumption of a commodity. The first is the "primrose path" theory of Herrnstein and Prelec (1992); the second is the "rational addiction" theory of Becker and Murphy (1990). The third and fourth theories to be discussed attempt to specify economic properties of some substances that might cause those substances to become addictive- the economic origins of addiction. These are Stigler and Becker's (1977) theory of how the price of a commodity may vary with its consumption and an elaboration of the Stigler-Becker theory called "relative addiction."

\section{THE HERRNSTEIN-PRELEC THEORY}

Figure 1 is similar to diagrams drawn by Herrnstein and Prelec (1992) to illustrate what they call "the primrose path." The primrose path works through "melioration" (Herrnstein \& Vaughan, 1980), which is choice of the highest local reinforcement rate-that is, the highest local increase in utility. Assume that a subject is choosing repeatedly between two alternatives, $X$ and $Y$. The horizontal axis of Figure 1 shows the relative overall rate of choosing $X,[X /(X+Y)]$. Relative overall rate is measured over some large but finite time window. In experiments with nonhuman subjects, on which the theory is based, the window may extend over only a few minutes.

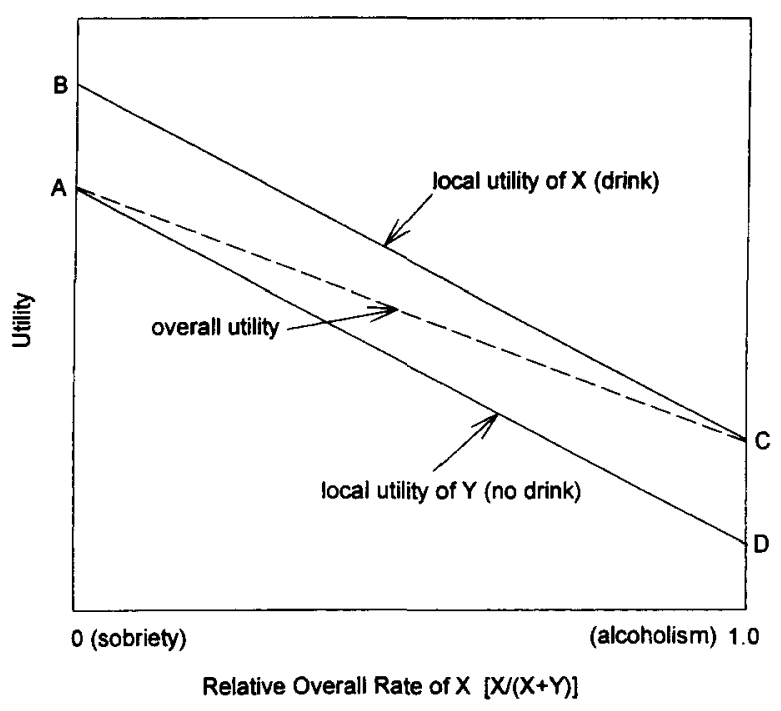

Figure 1. Utility as a function of relative rate of consumption of a commodity, $X$, according to the Herrnstein-Prelec theory. Overall utility decreases with consumption of $X$, but the local utility of $X$ is always greater than that of its alternative $(Y)$. The labels in parentheses show how the theory models a sample addiction-alcoholic drinking.
In the extension to human addiction, the window is presumed to extend over days, weeks, months, or years. As choices of $X$ and $Y$ accumulate, relative overall rate of $X$ changes accordingly. But relative overall rate also changes as time passes and past choices drop out of the window. If the window is large, encompassing many choices, movement along the horizontal axis will be correspondingly slow. For example, suppose that in the past you have exclusively eaten chicken dinners $(Y)$, and now begin to exclusively eat hamburger dinners $(X)$; if the window representing overall duration is 1 day long, the last chicken dinner eaten will leave the window, and the overall rate of hamburgers eaten will jump from zero (the left-most point in Figure 1) to 1.0 (the right-most point), in 1 day. If, however, the window were 1 year long, it would take 1 year for the last chicken dinner to exit from the window and for the overall percent of hamburgers to move from 0 to 100 .

The solid lines of Figure 1 represent local utilities of $X$ and $Y$. Local utilities occur over a much shorter period than overall utilities. Here they represent utilities of a single instance of consumption of $X$ or $Y$. Two features of Figure 1 are important. First, the local utility of $X$ is always higher than the local utility of $Y$ (the solid line labeled $X$ is above that labeled $Y$ ). Second, the greater the relative overall rate of $X$, the less the utility of both $X$ and $Y$ (both solid lines slope sharply down to the right). Consequently, the average utility over the duration of the time window (the overall utility) decreases as the relative overall rate of $X$ increases (the dashed line slopes downward to the right). The contingencies illustrated in Figure 1 pit local against overall utility. Repeated choice of the alternative with the higher local utility $(X)$ inevitably results in lower overall utility. On the other hand, in order to maximize overall utility, a subject would have to repeatedly choose the alternative with the lower local utility $(Y)$.

The labels in parentheses show how the HerrnsteinPrelec theory applies to an example of addictive behavioralcoholism. The horizontal axis now represents the relative overall rate of drinking or, in economic terms, the "stock" of drinking. The upper and lower solid lines represent utilities of accepting and refusing a single alcoholic drink. Note that whether drunk or sober, it is always immediately better to have a drink than not to have one. However, as the effects of drinking accumulate in the drinker's body (in the form of deteriorating health) and in the drinker's environment (in the form of deteriorating social relationships and economic well-being), overall utility decreases. In other words, while it is always (whether drunk or sober) immediately better to have a drink than not to have one, drinking decreases utility in the long run.

The path from A to B to C is the "primrose path." $\mathrm{A}$ meliorating subject-one who always chooses the alternative with the highest local utility--would invariably take this path. It is a dangerous path, however, because the immediate benefit of the transition from $A$ to $B$ is 
more than offset by the slow decline in utility from $B$ to C. The reverse path-from $C$ to $D$ to $A-$ might be called the "straight and narrow path." But a meliorating subject would never take this path, would never move away from $C$.

In Figure 1, the only stable point is at C, complete addiction. But the Herrnstein-Prelec model allows for other possibilities. The solid lines might not be parallel, might not be straight, and might cross at one or more points. For example, the possibility that at low rates alcoholic drinking increases overall utility (in terms of social facilitation and even health) would be incorporated into the model by rising and then falling solid lines. Crossing points (points of equal local utility) allow for stability wherever they occur. Nevertheless, because it rests on strict melioration, the Herrnstein-Prelec model is limited. In economic terms, the meliorating consumer (relying solely on local utilities and completely blind to overall utilities) is "myopic." A meliorating consumer completely ignores the effects of present consumption on future utility. Such a consumer, choosing between chicken and hamburger, would always choose whichever were preferred at the moment, ignoring possible differences in weight gain, health, or heartburn to be suffered later.

Of course people often do take into account the effects of current consumption on future utility. To account for such choices, Herrnstein and Prelec (1992) proposed a process of restructuring local utility. Recall that final causes and their effects are relative concepts. Local and overall utilities are correspondingly relativistic. While the utility of eating a hamburger is local relative to hamburger plus heartburn, hamburger plus heartburn is local relative to hamburger plus heartburn plus weight gain. As restructuring incorporates more and more context into local utility, maximization of local utility (melioration) approaches maximization of overall utility. As Herrnstein (1997, p. 272) said, "Anything that makes it easier for a subject to redefine the response categories [restructure the alternatives] will make it easier to maximize [to maximize overall utility]."

Heyman and Tanz (1995), in an experiment with pigeon subjects choosing among food reinforcers by pecking keys, have shown that breadth of context incorporated into local utility can be brought under stimulus control. The contingencies roughly corresponded to those of Figure 1 in that maximization of local utility (in this experiment, local reinforcement rate) was pitted against maximization of overall utility (in this experiment, overall reinforcement rate). A signal (a white light) indicated when overall reinforcement (over a span of many pecks) was increasing. Another signal (a blue light) indicated decreases in overall reinforcement rate. With the signals, pigeons did behave so as to maximize overall utility. Without the signals, they maximized local utility (and did not maximize overall utility). On the basis of these results, Heyman (1996b) has applied the Herrnstein-Prelec theory to a diverse variety of addic- tion phenomena. For example, during the Vietnamese war, many GIs became addicted to opium. Yet, when they came home, despite withdrawal symptoms and continued drug availability, the large majority of them did not resume the habit. Heyman attributed the change to stimulus control of the structure of local utility. In Vietnam, life could be short and social relationships, brief. Local utility was correspondingly narrow. At home, on the other hand, the presence of family and civilian career acted, according to Heyman, like the pigeons' white and blue lights - these signals restructured local utility so as to incorporate more context.

The problem with the Herrnstein-Prelec theory is that it provides no motive for restructuring. In the Heyman and Tanz (1995) experiment, for example, the local utilities were by definition relatively distinct while, without the white and blue lights, overall utility was relatively indistinct. With the lights, overall utility became as well signaled as local utility. Now, when overall utility was pitted against local utility, the pigeons maximized overall utility. Why? Without assuming a tendency to restructure alternatives as widely as possible (i.e., to maximize overall utility), a theory based on melioration (maximization of local utility) has no answer.

An economic account of addiction would not have the above problem because, as previously indicated, maximization of overall utility is the fundamental assumption of modern economic theory. Except for this fundamental assumption, and some terminological differences, the Becker-Murphy (Becker \& Murphy, 1990) theory of "rational addiction" is very much like the HerrnsteinPrelec theory. This similarity is emphasized in the present presentation of both theories. Both theories are simplified-but nothing essential has been omitted from either.

\section{THE BECKER-MURPHY THEORY}

A comparison of Figures 1 and 2 reveals the major similarities and differences between the HerrnsteinPrelec and Becker-Murphy theories. According to Becker and Murphy (1990), harmful addiction is a consequence of two opposing processes, "tolerance" and "reinforcement." The latter process overlaps but is not identical to the psychological process of the same name. (To avoid confusion, quotes will be retained for "reinforcement" as used in the Becker-Murphy theory.) "Tolerance" stands for the decrease in overall utility due to a person's "stock" of the addictive substance. Stock increases with consumption and depletes over time. Stock is equivalent to relative overall rate in the Herrnstein-Prelec theory. Just as choices of $X$ and $Y$ enter the time window as they occur and leave some time after, so they accumulate and dissipate in stock. As in the Herrnstein-Prelec theory, overall utility varies inversely with stock. For example, the more alcohol a person has drunk over the past 6 months (beyond a certain point), the more likely he/she is to be in bad health, to be out of a job, to have antagonized family and friends, and so on. This would be true 


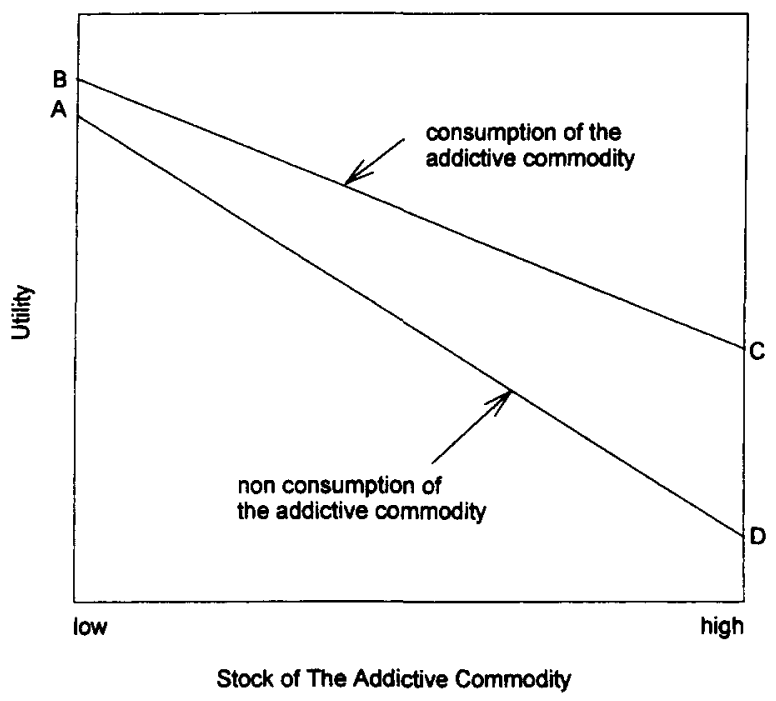

Figure 2. Utility as a function of stock of an addictive commodity according to the Becker-Murphy theory. The essential difference between this and Figure 1 is the wider spacing between points $C$ and $D$ relative to $A$ and $B$.

even if at present the person were sober. However, although utility decreases as stock increases ("tolerance"), the immediate gain in utility from current consumption of the addictive substance increases as stock increases ("reinforcement"). "Reinforcement" is illustrated by the divergence of the solid lines in Figure 2. Although such divergence is not inconsistent with the HerrnsteinPrelec theory, it is absolutely essential in the BeckerMurphy theory.

"Reinforcement," according to Becker and Murphy (1990), is an increase in utility for a given amount of consumption as stock increases. Following along with the example of the alcoholic, although the alcoholic may be much more miserable than the social drinker (due to "tolerance"), the alcoholic gets a greater immediate boost in utility from having a drink than the social drinker does (due to "reinforcement"). Consumption of the substance at any given moment has two effects. It immediately increases utility from line A-D to line B-C, and it adds slightly to the stock (moving down to the right in the diagram). These two effects may be assigned different weights in determining overall utility. Thus, in the BeckerMurphy theory, "tolerance" and "reinforcement" oppose each other just as, in the Herrnstein-Prelec theory, local and overall utilities oppose each other. ${ }^{2}$

But the Becker-Murphy theory goes further, positing a process of "rational addiction," even when future events are taken into account-when the consumer is not myopic. The rational consumer, according to Becker and Murphy (1990), does take all future events into account when choosing to consume or not. Overall utility is calculated on the basis of future as well as present "reinforcement" and "tolerance." But future events are discounted. Let us consider two extremes. At one extreme is a truly farsighted consumer, one who does not discount future events at all and weighs future utility, no matter how distant, equally with present utility. Such a person could never be an addict. In Figure 2, point $C$ and its environs (alcoholism) is lower than point $\mathrm{A}$ and its environs (social drinking). Because point $\mathrm{A}$ represents a stable state that may be enjoyed indefinitely, a nondiscounter would simply choose point A regardless of how difficult it was to get to that point; the benefits would eventually outweigh the costs. At the other extreme is a myopic consumer, one who cannot see beyond the next change in utility. Such a person would, regardless of current state, inexorably follow the primrose path to $\mathrm{C}$, to addiction. Between these extremes, the degree to which future utility is discounted will determine whether or not a given person becomes an addict. The more discounting, the more likely is addiction.

Consider the addict at point $\mathrm{C}$ who might be considering whether to quit. The fastest way to get to point $\mathrm{A}$ is to stop consuming the addictive substance right now (so as to deplete stock). If an addict suddenly stopped consuming the addictive substance, utility would drop to a point just to the left of $D$ and then crawl slowly up the line from D to A, presenting a constant, albeit decreasing, temptation to defect from this ("straight and narrow") path. Of course, as noted above, a farsighted nondiscounter would not hesitate to take this path since, once at A, the higher utility could be enjoyed indefinitely. But to the degree that the value of future enjoyment was discounted, the addict might very well decide not to take the difficult path. This much "rationality" is explicit in the Becker-Murphy theory and implicit in the HerrnsteinPrelec theory, since the latter does not deny that future events are discounted. ${ }^{3}$

Now consider the social drinker again. It appears from Figure 2 that, at point $\mathrm{A}$, the temptation to consume the addictive substance must be very small. At that point the immediate gain in utility from consumption (from point $A$ to just to the right of point $B$ ) is at its smallest and might be outweighed by future losses, even if they were discounted. The distinctive feature of the Becker-Murphy theory, however, is that under certain conditions, the theory posits reasons to follow an addictive path from $A$ to C. Even though at $A$ the present gain for consumption is low, the prospective addict would, by consuming the addictive substance and increasing stock, eventually reach a point where the gain for consumption will be high. If the increase in gain ("reinforcement") were weighted highly, present (low-gain) consumption, at or near A, would be seen as a sort of investment in future (highgain) consumption, at or near D. Becker and Murphy (1990) called this phenomenon adjacent complementarity. It is as if the addict were buying left shoes at an earlier time and right shoes at a later time. Left shoes by themselves are worth little or nothing but would be in a sense an investment in the enhanced value of right shoes later. In the Becker-Murphy theory, it is adjacent complementarity that drives "rational" (i.e., farsighted) consumers 
to become addicts. Adjacent complementarity could cause addiction even if the current gain in utility from consumption were zero (even if, in Figure 2, the distance between A and B were zero). What counts, for present consumption, is not only its effect on present utility but also its instrumentality in increasing the gain in utility from future consumption. (This is the fundamental point of departure between the Becker-Murphy theory and the Herrnstein-Prelec theory, which counts only present gain from present consumption.) Although adjacent complementarity depends on a farsighted consumer, this process cannot overcome the basic fact that $\mathrm{C}$ is lower than A. Thus, addiction still depends on discounting. Adjacent complementarity merely makes this dependence less complete than it would otherwise be.

Becker and Murphy (1990) cited three factors that influence whether a given person will become an addict or whether a given substance will be addictive. The first is the time discount rate, which may vary across commodities (Raineri \& Rachlin, 1993), across individuals (Mischel, 1966), and within individuals as they age (Green, Fry, \& Myerson, 1994). The second is the rate of dissipation of stock with time spent not consuming. This is the rate of movement upward to the left from D to A during nonconsumption. All else being equal, the faster stock dissipates (or the narrower the time window) the greater will be the difference in utility between $\mathrm{A}$ and $\mathrm{C}$, and the less tendency there will be for addiction to occur. The third factor is the extrinsic price of the commodity, in terms of money, risk (of jail), or time spent to obtain the commodity. An addict at point $\mathrm{C}$ might find the immediate drop in utility from $C$ to $D$ too great to overcome the delayed (hence discounted) rise from D to $\mathrm{A}$. But, as extrinsic price increases, net utility gained by consump-

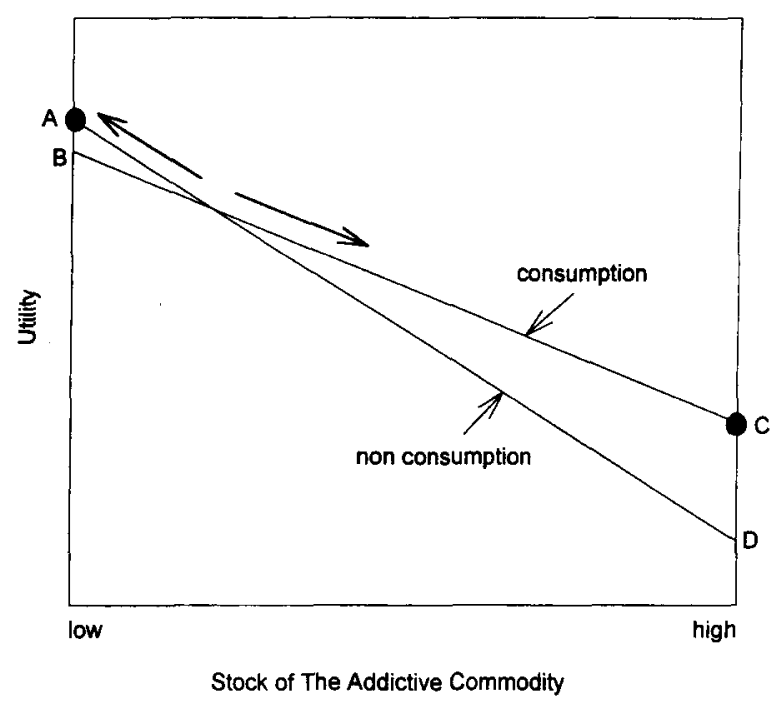

Figure 3. Same as Figure 2, except that the price of consumption has been lowered relative to its alternative, resulting in bistable equilibrium at $\mathrm{A}$ and $\mathrm{C}$. tion decreases and line B-C drops in height; with a higher extrinsic price, the drop in utility between $\mathrm{C}$ and $\mathrm{D}$ would be less, and the rise from $\mathrm{C}$ to $\mathrm{A}$ greater. A rise in price may therefore destabilize addiction and start the addict on the path to $A$.

Both the Herrnstein-Prelec and Becker-Murphy theories allow for bistable conditions. Figure 3 illustrates such conditions with lines A-D and B-C parallel to those of Figure 2 but crossing near the left of the diagram. To the left of the intersection, nonconsumption would be more locally valuable than consumption (A-D above BC); repeated choices not to consume would reduce stock by attrition; the myopic consumer would move gradually to the left, as shown by the arrow, coming to rest at $\mathrm{A}$. To the right of the intersection, stock would increase; the myopic consumer would move to the right, as shown by the arrow, coming to rest at $\mathrm{C}$. Thus, with intersecting lines, consumption could stabilize on the left or the right axis depending on whether the starting point were to the left or right of the intersection point. The difference between the Becker-Murphy and Herrnstein-Prelec theories is that the former contains an additional force (adjacent complementarity) that takes into account future as well as present possibilities. Thus, even to the left of an intersection, the wide distance between $\mathrm{C}$ and $\mathrm{D}$, representing relatively large rewards for future consumption (assuming that stock were built up by present consumption), would add weight to a decision to consume. Temporary extrinsic changes in the price of consumption or nonconsumption would raise or lower the lines, moving the intersection point to the left or right, shifting incentives, and perhaps sending consumers from one axis to the other (converting addicts to nonaddicts and vice versa).

Herrnstein and Prelec (1992) explicitly rejected "rational addiction," but the rationality in the BeckerMurphy model implies only that choice is based on maximization of discounted utility, not that a person sits down one day and consciously decides to be an addict. The addict is no more or less rational than a rat in a behavioral economics experiment that maximizes utility by allocating its time between eating and drinking (Rachlin, Battalio, Kagel, \& Green, 1981) or a frog that catches a fly by determining a (future) point of intersection between the path of its tongue and that of its target.

Both the Herrnstein-Prelec and Becker-Murphy theories as presented here take for granted the opposing forces diagrammed in Figures 1, 2, and 3. The two theories described below attempt to provide an economic explanation of those forces.

\section{THE STIGLER-BECKER THEORY}

Harmful addictions, according to Stigler and Becker (1977), arise from a combination of inelastic demand and a process I call "price habituation." Inelastic demand means that consumption is insensitive to price. This im- 


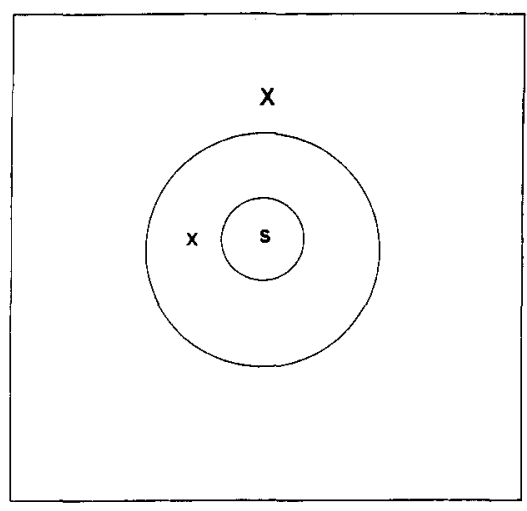

Figure 4. A field of elements constituting economic commodities. Circle $X$ represents a given commodity consisting of two classes of elements, those satisfying a certain need (s) and those not satisfying that need $(x)$.

plies that few other goods can substitute for the one in question. Demand for necessities such as food, clothing, and shelter is, by definition, highly inelastic.

Although the money price of a good may remain constant, there are some goods (common addictive substances are notorious examples) for which, as consumption rises, more and more of the good seems to be required to achieve the same effect. The need for an addictive good apparently rises with its consumption. However, instead of assuming that need rises, Stigler and Becker (1977) assumed that need stays constant but real price (money price plus all other costs) rises.

Figure 4 illustrates a hypothetical mechanism that could account for price habituation. The outer circle stands for a commodity, $X$, consisting of various elements. Some set of these elements, $s$, satisfies a certain need or drive, and some other set, $x$, does not satisfy that need or drive; but $X$ has to be bought as a whole $(s+x)$ to get $s$. A consumption-induced price increase (price habituation) results when the ratio of $s$ to $x$ decreases as more and more of $X$ is consumed. Even though the price of $X$ may remain constant, the price of $s$ effectively goes up (as when cereal manufacturers raise prices by keeping box size and price per box constant but reducing the ratio of cereal to air in the box).

Given this mechanism, the neophyte alcoholic and the experienced alcoholic would have equal needs for alcohol but, for the neophyte, $s$ would be relatively large per ounce of alcohol. Thus, for the neophyte drinker, the price of satisfying the need for alcohol would be less than it is for the experienced alcoholic. As the neophyte becomes more and more experienced, $s$ would shrink relative to $x$-and, although alcohol's money price ( $\$$ per unit of $X$ ) stays constant, its real price ( $\$$ per unit of $s$ ) would rise. This is price habituation. In combination with inelastic demand for $s$, it can account for acceleration of consumption. As consumption proceeds, inelasticity of demand for $s$ would draw resources from other goods. Withdrawal of the addictive substance $(X)$ would have harmful effects because demand for $s$ is assumed to be inelastic-there are no substitutes for $s$; no other goods contain it. This is why, according to Stigler and Becker (1977), harmful addictions go together with habituation or tolerance for the addictive substance.

"Beneficial addictions," on the other hand, are said by Stigler and Becker (1977) to arise from a combination of highly elastic demand and what I call "price sensitization." Elastic demand means that consumption is highly sensitive to price. This implies that many other goods can substitute for the one in question to satisfy a need or drive (many goods contain $s$ ). The demand for moviegoing, for example, is elastic; a consumer could go to a play, watch television, and so on. Thus, for an individual, moviegoing is sensitive to price. When the price of moviegoing goes up (relative to the price of its substitutes), the average person will go to fewer movies.

But it is also true that the experienced moviegoer, the movie expert, gets more (or a higher level of) satisfaction from a given amount of moviegoing than the neophyte does. The expert knows more about the actors, directors, other similar films; this context enriches the expert's experience of the movie. Thus the price of a given amount of time in a movie theater is lower ( $s$ is a greater fraction of $X$ ) for an experienced moviegoer than for a novice; the novice has to see more movies (and thus pay more) to get the same satisfaction as the expert. This is price sensitization. In combination with elastic demand, it would cause more and more moviegoing; as more movies are watched, their real price (cost per unit of $s$ ) would go down; but as price goes down, elastic demand would cause a rise in moviegoing, which, in turn, would cause the real price to descend further, and so forth. But such addictions would not normally be harmful because if the money price of a beneficial addiction were to rise sharply, or if the good $(X)$ were suddenly cut off, there would be plenty of substitutes; consumption of $X$ would simply drop. ${ }^{4}$

A problem with the Stigler-Becker theory is that realworld studies of harmfully addictive substances have frequently shown demand for those substances to be relatively elastic. Becker et al. (1992) cited several instances: Chaloupka (1991) for cigarettes; Cook and Tauchen (1980) for alcohol; Mobilia (1990) for gambling; Nisbet and Vakil (1972) for marijuana; Silverman and Spruill (1977) for heroin. Moreover, psychologists studying consumption by individuals in the laboratory have found that consumption of cigarettes, alcohol, cocaine, heroin, and other drugs is relatively responsive to price (DeGrandpre \& Bickel, 1996; Heyman, 1996a; Vuchinich \& Tucker, 1996b). That is, demand for these commodities is elastic. Although, as noted above, Stigler and Becker (1977) did discuss a kind of addiction compatible with elastic demand, such addictions are generally thought to be beneficial, or at least not harmful.

But Stigler and Becker (1977) proposed their theory of addiction only as an illustration, among several others, of how apparently changing tastes could be described in 
terms of constant utility functions. An elaboration of the Stigler-Becker theory, called "relative addiction theory," makes it flexible enough to account for elastic demand for addictive substances and also compatible with the Herrnstein-Prelec and Becker-Murphy theories described above.

\section{RELATIVE ADDICTION THEORY}

In what follows we will drop the economist's language of "commodities" and "goods" and adopt the psychologist's language of "consumption activity." In other words, it is assumed that consumption creates utility (Premack, 1965; Rachlin et al., 1981; Rachlin \& Burkhard, 1978). Suppose there were two activities, $X$ and $Y$, fairly substitutable for each other but not substitutable for anything else. Suppose, for example, some consumption activity, $s$, were necessary for life and that deprivation of $s$ created a strong demand for it. Suppose, moreover, that $s$ were available through only a small number of consumption activities - say two, $X$ and $Y$. Then $X$ and $Y$ would be at least to some extent mutually substitutable but, as a pair, relatively nonsubstitutable for other consumption activities. In a sense, $X$ and $Y$ would be in a compartment together, walled off from other activities. In economic terms, the commodities consumed would be "separable" (Becker, 1976, Part IV). The demand for $s$ would be inelastic because by assumption there is no substitute for $s$. But the demand for $X$ would be elastic because there is a substitute- $Y$. Recent evidence for high demand elasticity of addictive activities like drinking alcohol (Heyman, 1996a; Vuchinich \& Tucker, 1996a) and smoking cigarettes (Fisher, 1996) would, therefore, be consistent with the theory. Figure 5 diagrams the situation. Activities $X$ and $Y$ each contain some $s$ along with other components $(x$ and $y$ ) that distinguish them ( $X$ from $Y$ ), but no other activity contains any $s$.

The theory's mechanism of addiction thus depends on mutual substitutability. But it also depends on price habituation of one of the activities and price sensitization of the other. In the next section we consider evidence for the existence of such pairs of activities, but for the sake of explicating the mechanism, let us simply assume that

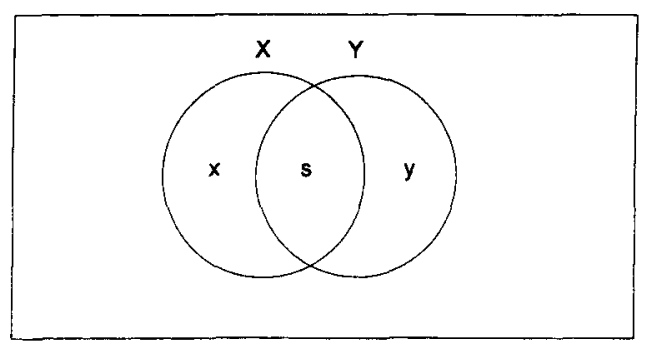

Figure 5. A field of elements constituting various consumption activities. The circles represent individual activities. Activities $X$ and $Y$ both contain $s$. because of their differing non-s qualities ( $x$ and $y$ ), $X$ is price habituated and $Y$ is price sensitized. That is, the more activity $X$ is performed, the higher the real price of $X$; the more $Y$ is performed, the lower the real price of $Y$. This yields the double downward sloping lines of Figures 1,2, and 3; increases of $X$ and decreases of $Y$ both decrease utility (via increased price).

Suppose that initially $Y$ were cheaper than $X$ but, because of extrinsic economic forces, the money price of $X$ were suddenly and sharply reduced. Because $X$ and $Y$ are mutually substitutable (to a degree), and because $s$ is in demand, the now-cheap activity $X$ would increase in rate and $Y$ would decrease. If $X$ increases, its real price would rise (due to price habituation); if $Y$ decreases, its price would also rise (due to reduction in price sensitization). If the rise in the real price of $X$ were less than the rise in the real price of $Y$, more of $X$ (and less of $Y$ ) would again be bought, which, for the same reason as before, would increase the price of $Y$ relative to $X$. Again, more resources would be devoted to $X$, and so forth, until all available resources were devoted to $X$ (and $Y$ not bought). This is the proposed mechanism underlying addiction to $X$. As in Figures 1, 2, and 3, increases of activity $X$ relative to $Y$ increase the price (equivalent to decreasing the local utility) of both activities. The appendix mathematically derives conditions for harmful addiction $(X / Y \rightarrow \infty)$, beneficial addiction $(X / Y \rightarrow 0)$, and stability ( $X / Y \rightarrow$ a constant $)$.

In summary, according to relative addiction theory, consumption of the addictive substance creates an increase in price of both the addictive activity $(X)$ and its substitute $(Y)$. Addiction occurs when $X$ remains cheaper than $Y$ throughout consumption. (It is this state of affairs rather than Becker and Murphy's [1990] "adjacent complementarity" or Herrnstein and Prelec's [1992] "melioration" that creates the primrose path illustrated in Figures 1,2, and 3.) Repeated choice of $X$ over $Y$ (the cheaper over the more expensive source of $s$ ) leads the addict to a point where the price of both activities is maximal. Herrnstein and Prelec took this contingency pattern as a given. Here, we derive it from basic economic principles.

The next section cites evidence that two activities, smoking and social interaction, are (to a degree) mutually substitutable, and argues that smoking is price habituated while social interaction is price sensitized. Again, for the sake of explication, let us assume this to be the case. (Replace the label "consumption" in Figure 3 with "smoking" and "nonconsumption" with "social activity.") Applying the assumptions to these specific activities: (1) Smoking and social interaction are mutually substitutable activities; (2) smoking is price habituated - the more cigarettes smoked, the more smoking costs (i.e., less pleasure is gotten from each successive cigarette); and (3) social interaction is price sensitizedthe more social activity, the less (time, effort, and money) social interaction costs (i.e., social support needs to be maintained to be effective). 
Now suppose either the price of smoking suddenly decreases or a person suddenly loses social support (say, a close friend or relative dies). Because these activities are substitutable, the person starts smoking a bit more and withdrawing a bit from social activities. Both activities now increase slightly in price-smoking $(X)$ because of price habituation-social interaction $(Y)$ because of reduction in sensitization. Let us first assume that the price habituation of smoking is more sensitive than the price sensitization of social interaction (implying that the relative slopes of A-D and B-C in Figure 3 are reversed). This is relative price habituation. Then the increase in the price of smoking would be greater than that of social interaction. Given this increase in the relative price of smoking, the person would now turn back to social activities to obtain $s$ (whatever is gotten from these activities in common). This turning back would decrease the real price of social interaction further (due to price sensitization), but it would also decrease the price of smoking (due to loss of habituation). By the assumption that price habituation is more responsive to consumption than is price sensitization, the decrease in the price of smoking would be greater than that of social interaction. So the person would smoke more. Again, this would increase the relative price of smoking, causing the person to smoke less. In other words, there would be an oscillation about a point of equilibrium, finally settling on a ratio of smoking and social activity that maintains a balance. (In Figure 3, the direction of both arrows would reverse, and consumption would be stable at the intersection.) Thus, relative price habituation would not produce the runaway tendency to consume that characterizes addiction.

Now, however, consider what happens with relative price sensitization (A-D steeper than B-C, as in Figure 3). Now when a person shifts to more smoking (because the extrinsic price of cigarettes suddenly decreases or that of social interaction suddenly increases), the subsequent increase in the price of smoking (due to price habituation) would not be as great as the subsequent increase in the price of social interaction (due to loss of sensitization). Now the person could not get as much $s$ as before from (much more expensive) social interaction and would have to get more from (not so much more expensive) smoking. So he/she would smoke more and socialize less. This would raise the relative price of socializing still more, causing still more smoking and still less socializing, until finally socializing would become prohibitively expensive; all $s$ would be gotten from smokingeven though that, too, would be very expensive. Relative consumption of smoking $(X / Y)$ has become infinite. Thus, relative price sensitization would produce the runaway tendency to consume that characterizes addiction.

\section{EVIDENCE FOR RELATIVE ADDICTION THEORY}

Do cigarette smoking and social interaction behave as commodities $X$ and $Y$ are here supposed to behave? Re- cent evidence indicates that they do. On the basis of several studies of smoking and "social support" (the commodity corresponding to the activity of social interaction), Fisher (1996) summarized evidence for their mutual substitutability: People with more social support smoke less than those with less social support; smoking cessation programs work better when they are accompanied by increased social support; the sudden withdrawal of social support (e.g., by widowhood or divorce) tends to be accompanied by an increase in smoking.

Fisher stated (p. 227):

(a) Similar operations such as stressful events, personal losses, and performance challenges are likely to instigate choices for either social support or smoking.

(b) Psychological effects such as depressed mood, anxiety, or need for arousal appear to follow the operations noted in (a) and to be associated with increased interest in both smoking and social support.

(c) The common effects of social support and smoking appear to include anxiety reduction, mood elevation and performance enhancement.

Although smoking and social interaction may be substitutable for each other, they are clearly different in terms of the relation between consumption and demand. Nicotine generates its own antagonists in the body (McMorrow \& Foxx, 1983); therefore, up to a point, greater and greater doses of the drug are required to have the same mood-elevating effect. This is price habituation. Of course, at first, there is a degree of sensitization as the neophyte learns to smoke, but once this threshold is crossed, smoking may accelerate to an extreme (U.S. Department of Health and Human Services, 1988). The relation between the demand for social support and its consumption would seem to be more complex. For most children, social interaction is freely available (i.e., cheap), but eventually considerable skill must be acquired to maintain it (Ainsworth \& Bowlby, 1991). In new social circumstances the skill must be altered or reacquired; without practice, it grows rusty. (This is why baseball players need spring training after a winter of inactivity.) By the time adulthood is reached, some people are clearly better than others at securing and maintaining social activity (Fisher, 1996). It is thus fair to say that social interaction is in general price sensitized-the more it is performed, the cheaper it gets, the less it is performed, the more expensive it gets.

If social interaction and cigarette smoking are substitutable, what is the common need or drive that they satisfy? Fisher (1996) speculated that anxiety reduction, mood elevation, and performance enhancement are the common factors. These psychological factors may achieve their effects through different mechanisms, or they may be common effects of a single mechanism such as a hormone or stimulation in a certain area of the brain. Green and Rachlin (1991) found that hypothalamic electrical brain stimulation was partially substitutable for both eating and drinking, two commodities not at all substitutable for each other. It should not be surprising, there- 
fore, that two such apparently diverse activities as smoking and social interaction are mutually substitutable. In any case, the question, What is the mechanism of $s$ ? is beyond the scope of a teleological theory. Nevertheless, if the present theory is correct, the addictive nature of smoking lies not in some special physiological properties unique to smoking, but in the fact that it is price habituated and also substitutable for a price-sensitized activity. The elasticity of demand for cigarettes would be due, not to an elasticity of demand for anxiety reduction, mood elevation, and performance enhancement, but to the fact that these essential (i.e., nonelastic) reinforcers are available from social interaction as well as smoking.

It seems reasonable to suppose that social interaction would be substitutable for other addictive activities such as consumption of alcohol and other drugs. Indirect evidence for such substitutability is the high price elasticity of these activities (DeGrandpre \& Bickel, 1996; Heyman, 1996a; Vuchinich \& Tucker, 1996b). More direct evidence comes from a study by Vuchinich and Tucker (1996b) of relapse of alcoholics who had participated in a treatment program. Relapse was significantly more frequent among those with low social support.

Schuster et al. (1995) examined outcome data from a voucher-based treatment with injecting heroin abusers in methadone treatment who also had a history of heavy cocaine abuse. The treatment program successfully reduced cocaine use among most of the addicts. However, a disproportionately large fraction of program participants had been diagnosed as having an antisocial personality disorder (APD), and the program was notably unsuccessful with those subjects. Thus it appears that APD is linked with drug use in the first place and when present, retards treatment. This is what would be expected if drugs could substitute for social support.

Whether or not the present theory is correct, high price elasticity for addictive activities means that something must be substitutable for them. Social interaction seems a likely candidate. If so, Figure 5 would become more complex. Different activities would overlap differently. If $X$ and $Z$ were price habituated activities (like smoking and drinking) and $Y$ were price sensitized (like social interaction), then a person's addiction to $X$ or $Z$ would depend on $X$ 's and $Z$ 's respective initial prices and on relative price habituation or price sensitization between each pair. Assuming $X$ and $Z$ to be about equally price habituated and $Y$ to be relatively price sensitized with respect to them both, there would be a tendency to alternate between $X$ and $Z$ (to be addicted to both!). However, if the prices of $X$ and $Z$ were different, and $X$ and $Z$ were between themselves highly substitutable, all consumption would go to the cheaper of the two.

In real social systems, the price of social interaction (in terms of time, effort, and money) varies very widely. For children whose parents care for them, the price is essentially zero; for children whose parents do not care for them, the price must be prohibitive. For adults, the gain or loss of family and friends can cause sharp variations in price. We should, therefore, expect addiction in general to vary widely and (compensating for price) be inversely proportional to the price of social interaction within any social group.

An important feature of the present model is its dependence on initial conditions. For each pair of commodities there is a point of stable or unstable equilibrium (see Appendix). With relative price sensitization, the bistable conditions illustrated in Figure 3 would apply. An interesting case arises when the negatively addictive activity becomes extrinsically instrumental for obtaining the positive commodity-for example, when smoking, drinking, or taking crack becomes a condition of social interaction. The phrase "social drinking" implies the pervasiveness of such a contingency. The social drinker drinks in part to reduce the cost of social support. In such circumstances, the initial ratio $X / Y$ (drinking/socializing) would not be zero and might be hovering just below equilibrium (just to the left of the intersection point in Figure 3). There, a small change in price (a reduction in the price of drinking or an incrcase in that of socializing) could tip the balance (by elevating B-C relative to A-D, as in Figure 2) and moving consumption to a single stable point at $\mathrm{C}$. By the time conditions of Figure 3 were restored, consumption could have come to rest at $\mathrm{C}$. At the other extreme, contingencies would work the other way. Addiction is usually socially condemned. But now, at C, the immediate negative effect of quitting (moving from $C$ to $D$ ) would far outweigh the negative effect of the condemnation.

Perhaps this is the reason for a phenomenon studied in cigarette consumption called "the ratchet effect" (Young, 1983); as the money price of cigarettes decreases, consumption rises; but when the money price later increases, consumption of cigarettes does not fall. Apparently, for cigarettes (and perhaps for other addictive commodities), the elasticity of demand differs for upward and downward variation of money price. According to the relative addiction model, a ratchet effect would occur in an individual if the decrease in the money price of cigarettes served to start him/her on the path to addiction (to push him/her over the $X / Y$ point of equilibrium). Once past the equilibrium point, he/she would progress to addiction $(X / Y \rightarrow \infty)$. At that point, it would take a massive price decrease to push him/her back over the equilibrium point. The model predicts, then, that the ratchet effect should be stronger the longer the interval between the initial price decrease and the subsequent price rise (because the longer the interval, the further toward addiction the person will have progressed). This has yet to be tested.

\section{LIMITATIONS}

A teleological and behavioral theory such as the present one can discover only the constants and variables pertaining to the behavior of a whole organism. It cannot discover the internal mechanisms underlying those con- 
stants and variables. A teleological theory can point to the properties that an essential variable, such as $s$, must have, but it cannot identify $s$.

A more crucial limitation of the present theory is that it is a theory of addiction or craving, not a theory of selfcontrol. Relative addiction theory describes the properties of addictive substances and explains why they are addictive but does not indicate how addictions may be controlled. Self-control theories such as those of Ainslie (1992) and Rachlin (1995) take as a given the demands for various substances but do not indicate, except in general terms, why certain commodities are addictive and others are not. The present theory, therefore, complements rather than substitutes for theories of self-control.

Relative addiction theory, like the Herrnstein-Prelec theory, is myopic. But, also like the Herrnstein-Prelec theory, it can accommodate discounting of future events. As with all theories discussed, more myopic individuals (those with relatively steep discount functions) are more likely than farsighted individuals (those with relatively shallow discount functions) to become addicts. The myopia in the present theory derives from the assumption that organisms maximize present utility based on present conditions. The theory takes account of how past consumption affects present prices but not of how present consumption affects future prices. When one activity $(X)$ is price habituated and the other $(Y)$ is price sensitized, increases of $X$ increase the price of both activities in the future. If this future increase were given its full weight in the present, addiction would not occur. Addictive behavior only occurs, therefore, when future events are sharply discounted. Theories of self-control are theories of how discounting may be avoided or circumvented. Ainslie (1992) suggested extrinsic or intrinsic commitment. Prelec and Herrnstein (1992) suggested restructuring of alternatives, and Rachlin (1995) suggested patterning of choices over time. All alike presuppose, beneath addiction, choice of a strong, brief, immediate reward (in conflict with its own, still stronger, harmful future effects). The present theory specifies the conditions under which such rewards are generated.

\section{IMPLICATIONS}

Relative addiction theory suggests that Fisher (1996) is on the right track to look for substitutability in such apparently disparate activities as cigarette smoking and social interaction. Discovery of other such price-sensitized substitutes for harmful addictions might lead to more effective treatment methods. Fisher's evidence implies that those who advocate making drugs more expensive and those who advocate social programs for addicts are both, in a sense, correct. Increasing the price of drugs and decreasing the price of substitutes (such as social support) should both tend to decrease drug taking. But to bring an addict all the way back to and over the point of unstable equilibrium, the relative price change would have to be very large (see Appendix). Perhaps both avenues should be pursued, but it may well be more difficult for society to increase the price of drugs to very high levels (say, by making criminal penalties severe and certain) than to reduce the price of social support to nearzero levels.

\section{REFERENCES}

AInsLie, G. (1992). Picoeconomics: The strategic interaction of successive motivational states within the person. New York: Cambridge University Press.

AINSWORTH, M. D. S., \& BowlBy, J. (1991). An ethological approach to personality development. American Psychologist, 46, 333-341.

BECKER, G. S. (1976). The economic approach to human behavior. Chicago: University of Chicago Press.

Becker, G. S., Grossman, M., \& MurPhy, K. M. (1992). Rational addiction and the effect of price on consumption. In $\mathrm{G}$. Loewenstein \& J. Elster (Eds.), Choice over time (pp. 361-370). New York: Russell Sage Foundation.

BeCKER, G. S., \& MURPHY, K. M. (1990). A theory of rational addiction. Journal of Political Economy, 96, 675-700.

Chaloupka, F. J. (1991). Rational addictive behavior and cigarette smoking. Journal of Political Economy, 99, 722-742.

Chung, S. H., \& Herrnstein, R. J. (1967). Choice and delay of reinforcement. Journal of the Experimental Analysis of Behavior, 10, 6774.

CoOK, P. J., \& TAUChEN, G. (1980). The effect of liquor taxes on heavy drinking. Bell Journal of Economics, 13, 379-390.

DeGrandPre, R. J., \& BickeI, W. K. (1996). Drug dependence as consumer demand. In L. Green \& J. H. Kagel (Eds.), Advances in behavioral economics: Vol. 3. Substance use and abuse (pp. 1-36). Norwood, NJ: Ablex.

Fisher, E. B., JR. (1996). A behavioral-economic perspective on the influence of social support on cigarette smoking. In L. Green \& J. H. Kagel (Eds.), Advances in behavioral economics: Vol. 3. Substance use and abuse (pp. 207-236). Norwood, NJ: Ablex.

Green, L., Fry, A. F., \& MYerson, J. (1994). Discounting of delayed rewards: A life span comparison. Psychological Science, 5, 3336.

Green, L., \& KaGeL, J. H. (EDs.) (1996). Advances in behavioral economics: Vol. 3. Substance use and abuse. Norwood, NJ: Ablex.

Green, L., \& Rachlin, H. (1991). Economic substitutability of electrical brain stimulation, food and water. Journal of the Experimental Analysis of Behavior, 55, 133-144.

Herrnstein, R. J. (1997). The matching law. Cambridge, MA: Harvard University Press.

Herrnstein, R. J., \& Prelec, D. (1992). A theory of addiction. In G. Loewenstein \& J. Elster (Eds.), Choice over time (pp. 331-360). New York: Russell Sage Foundation.

Herrnstein, R. J., \& VAughan, W., JR. (1980). Melioration and behavioral allocation. In J. E. R. Staddon (Ed.), Limits to action: The allocation of individual behavior (pp. 143-176). New York: Academic Press.

Heyman, G. M. (1996a). Elasticity of demand for alcohol in humans and rats. In L. Green \& J. H. Kagel (Eds.), Advances in behavioral economics: Vol. 3. Substance use and abuse (pp. 107-132). Norwood, NJ: Ablex.

Heyman, G. M. (1996b). Resolving the contradictions of addiction. Behavioral \& Brain Sciences, 19, 561-610.

Heyman, G. M., \& TANZ, L. (1995). How to teach a pigeon to maximize overall reinforcement rate. Journal of the Experimental Analysis of Behavior, 64, 277-298.

MCMorrow, M. J., \& Foxx, R. M. (1983). Nicotine's role in smoking: An analysis of nicotine regulation. Psychological Bulletin, 93, 302327.

Mischel, W. (1966). Theory and research on the antecedents of selfimposed delay of reward. In B. A. Maher (Ed.), Progress in experimental personality research (Vol. 3, pp. 85-132). New York: Academic Press.

Mobilia, P. (1990). An economic analysis of addictive behavior: The 
case of gambling. Unpublished doctoral dissertation, City University of New York.

NisBET, C. T., \& VAKIL, F. (1972). Some estimates of price and expenditure elasticities of demand for marijuana among U.C.L.A. students. Review of Economics \& Statistics, 54, 473-475.

Premack, D. (1965). Reinforcement theory. In D. Levine (Ed.), Nebraska Symposium on Motivation: 1965 (pp. 123-179). Lincoln: University of Nebraska Press.

RaCHLIN, H. (1978). A molar theory of reinforcement schedules. Journal of the Experimental Analysis of Behavior, 30, 345-360.

RaChLIN, H. (1992). Teleological behaviorism. American Psychologist, 47, 1371-1382.

RACHLIN, H. (1994). Behavior and mind: The roots of modern psychology. New York: Oxford University Press.

RaChlin, H. (1995). Self-control: Beyond commitment. Behavioral \& Brain Sciences, 18, 109-159.

Rachlin, H., Battalio, R., Kagel, J., \& Green, L. (1981). Maximization in behavioral psychology. Behavioral \& Brain Sciences, 4 , $371-419$.

Rachlin, H., \& BuRKhaRd, B. (1978). The temporal triangle: Response substitution in instrumental conditioning. Psychological Review, 85, 22-48.

RAINERI, A., \& RACHLIN, H. (1993). The effect of temporal constraints on the value of money and other commodities. Journal of Behavioral Decision Making, 6, 77-94.

Samuelson, P. A. (1937). A note on measurement of utility. Review of Economic Studies, 4, 155-161.

Schuster, C. R., Silverman, K., Harrell, S., Brooner, R., Cone, E. \& PRESTON, K. (1995). ASP as a predictor of treatment outcome in a contingency management program for cocaine abusers. Poster presented at the annual meeting of the American College of Neuropsychopharmacology, San Juan, Puerto Rico.

Silverman, L. P., \& Spruill, N. L. (1977). Urban crime and the price of heroin. Journal of Urban Economics, 4, 80-103.

STIGLER, G., \& BECKER, G. (1977). De gustibus non est disputandum. American Economic Review, 67, 76-90.

U.S. Department of Health and Human Services (1988). The health consequences of smoking: Nicotine addiction. A report of the Surgeon General (DHHS Publication No. 89-8411). Washington, DC: U.S. Government Printing Office.

VuCHINICH, R. E., \& TuCKER, J. (1996a). Alcohol relapse, life events, and behavioral theories of choice: A prospective analysis. Experimental \& Clinical Psychopharmacology, 4, 19-28.

VUCHINICH, R. E., \& TUCKER, J. (1996b). The molar context of alcohol abuse. In L. Green \& J. H. Kagel (Eds.), Advances in behavioral economics: Vol. 3. Substance use and abuse (pp. 133-162). Norwood, NJ: Ablex.

YouNG, T. (1983). The demand for cigarettes: Alternative specifications of Fujii's model. Applied Economics, 15, 203-211.

\section{NOTES}

1. Two prior causal principles, material causes and formal causes, were used by Aristotle to describe (nonmoving) substances. Material causes stand to formal causes as efficient to final. Formal and final causes were thought by Aristotle to be more scientific than material and efficient causes because they are more abstract, and therefore more general. Renaissance physics turned these priorities around. The teleological theories presented here are thus attempts to reestablish Aristotelian scientific principles in modern psychology on equal footing with those of Renaissance physics.

2. Point $\mathrm{A}$ is set at low consumption ("social drinking") rather than no consumption (abstinence) only for the sake of convenience. The difficult questions - How does a non-drug user first come to use an addictive substance? Is it possible for an addict to become a moderate user? Does moderate consumption of drugs require a higher or lower degree of self-control than does abstinence?-are beyond the scope of this article. (See Rachlin, 1995, for a discussion of the last question.)

3. Chung and Herrnstein (1967) proposed what economists believe to be an "irrational" (hyperbolic) discount function, whereas Becker and Murphy proposed a "rational" (exponential) function, but the operating cause of addiction in both models is discounting per se, not the particular discount function assumed.

4. The mechanism illustrated in Figure 4, the one to be illustrated in Figure 5, and the terms price habituation and price sensitization are used for explanatory purposes only. The actual physiological mechanisms underlying these processes are not specifiable by a teleological theory.

5. This explanation of the ratchet effect depends on the existence of an unstable equilibrium point, as in Figure 3 . Thus, a ratchet effect would also be predicted by the Herrnstein-Prelec and Becker-Murphy models with crossing consumption and nonconsumption lines (the bistable conditions discussed previously).

\section{APPENDIX The Conditions of Addiction}

We are looking for a function relating relative consumption at time $t,(X / Y)_{t}$, to relative consumption at time $t-1,(X / Y)_{t-1}$. Then we will examine when, as $t$ steps along, the function stabilizes, and when it progresses to extremes. The time marker, $t$, is here taken to represent an interval during which consumption activities $(X$ and $Y$ ) occur in various proportions (Rachlin $\&$ Burkhard, 1978). The utility of the package, $X_{t}, Y_{t}$ may be expressed as

$$
U=a X_{t}^{n}+b Y_{t}^{n},
$$

where $a$ and $b$ are scale factors and $n(<1)$ is a constant representing substitutability between $X$ and $Y$. Equation Al is called a CES function and much used to describe economic data. In psychology, Equation A1 has described consumption patterns of rats choosing between imperfect substitutes (food, water, flavored liquids, electrical brain stimulation), and it implies matching of relative responding to relative reinforcement (Rachlin, 1978). Thus, by extension, it accounts for all of the choice data with humans and nonhumans described by Herrnstein's matching law (Herrnstein, 1997).

As $n$ approaches 1.0, the activities approach perfect substitutability - the utility of the package approaches the simple sum of the quantities (times scale factors) consumed. For example, if $X$ were Coke and $Y$ were Pepsi, the utility of a mixed package of bottles of Coke and Pepsi would, for most consumers, be close to the total number of bottles in the package ( $a$ and $b$ allowing for different-sized bottles). Values of $n$ greater than 1.0 are conceivable but would imply that the marginal utility of an activity could increase as its amount increased. This would violate the law of diminishing marginal utility. We therefore assume that $n$ does not exceed 1.0 .

As $n$ approaches zero, the activities become less substitutable, like Coke and Seven-Up, and as $n$ becomes more and more negative the activities become complements, like Coke and pretzels. The usual illustrations of strong complementarity are left shoes and right shoes or bicycle wheels and bicycle frames. The concepts of substitutability and complementarity connect with the psychological concept of motivation in the sense that the more of an activity you do, the less you need or want its substitutes and the more you need or want its complements.

Let us assume further that at any period of time some fixed amount $\left(W_{t}\right)$ of resources (time, effort, money, or some combination of these) is available to distribute between $X_{t}$ and $Y_{t}$ :

$$
p_{t} X_{t}+q_{t} Y_{t}=W_{t},
$$

where $p$ and $q$ are true prices of $X$ and $Y$. Rachlin (1978) showed that utility (Equation Al, under constraints of Equation A2) is maximized when 


$$
\left(\frac{X}{Y}\right)_{t}=\left(\frac{p b}{q a}\right)_{t}^{\frac{1}{n-1}}
$$

As the activities become more and more substitutable $(n \rightarrow 1)$, $X / Y$ approaches zero or infinity depending on relative price; as suming $a=b$, if the true price $(p)$ of a unit of $X$ is higher than that $(q)$ of a unit of $Y$, then all consumption will go to $Y$, and vice versa (as is usually the case with Coke and Pepsi--people buy whichever is cheaper). If the activities are perfectly complementary (like wearing left and right shoes), then $n$ becomes negatively infinite and $X=Y$ (as is usually the case with left and right shoes-people wear them in pairs).

Now let us consider how Equation A3 would change over time with consumption of $X$ and $Y$. We are concerned here with relative, not absolute, consumption. Absolute consumption is regulated by the substitutability of $X$ and $Y$ in common for other activities. Since by assumption the demand for quality $s$ is inelastic ( $s$ is assumed to be available only from $X$ or $Y$ ), the absolute rate of consumption of $X$ and $Y$ together would be fairly constant. A simple expression of alteration of relative price with relative consumption is

$$
\left(\frac{p}{q}\right)_{t}=\left(\frac{X}{Y}\right)_{t-1}^{m}\left(\frac{p}{q}\right)_{t-1} \quad-1<m<1 .
$$

The exponent, $m$, referring to Figure 5 , is a measure of the shift in $s$ between $X$ and $Y$ from trial to trial. At $m=-1, X$ loses all $s$ and $Y$ gains all $s$. At $m=1, X$ gains all $s$ and $Y$ loses all $s$. One way to think of the limits on $m$ is to consider $m$ as a change in the fraction, $y^{\prime} /\left(x^{\prime}+y^{\prime}\right)$ from $t-1$ to $t$, where $x^{\prime}=x / X$ and $y^{\prime}=$ $y / Y$. If $X$ were completely price habituated and $Y$ completely price sensitized, $x^{\prime}$ would change from 0 to 1 and $y^{\prime}$ from 1 to $0(m=-1)$ in a single trial. At the other extreme, the reverse would occur $(m=1)$.

When $m=0$, relative price is independent of consumption. When $m>0$, relative price varies directly with prior relative consumption; this is relative price habituation. When $m<0$, relative price varies inversely with prior relative consumption; this is relative price sensitization.

Substituting Equation A3 in Equation A4:

$$
\left(\frac{X}{Y}\right)_{t}=\left(\frac{X}{Y}\right)_{t-1}^{\frac{m}{n-1}+1}
$$

Let us say the exponent $(m /(n-1)+1)=r$, and ask what happens as $r$ varies. When $r$ varies between 0 and $1.0, X / Y$ ap- proaches unity more or less rapidly from its initial value. At $r=$ $0, X / Y$ jumps immediately to unity. At $r=1.0, X / Y$ stays at its initial value. Thus, $0<r<1.0$ is a stable range for $X / Y$. However, if $r>1.0$ and $X$ is initially greater than $Y, X / Y$ grows to infinity. If $r>1.0$ and $Y$ is initially greater than $X, X / Y$ approaches zero. Thus, $r>1.0$ is an unstable range for $X / Y$. Negative values of $r$ mirror the effects of positive values, except stability is approached by oscillations of decreasing amplitude and extremes are approached by oscillations of increasing amplitude. We will assume here that $r$ is always positive (oscillations occurring within rather than between successive intervals).

Now let us consider the exponent, $m$, of Equation A4. Recall that for consumption of normal commodities, $n<1$. Thus, $n-1$ must be negative. For instability,

$$
\begin{gathered}
r=\frac{m}{n-1}+1>1, \\
\frac{m}{n-1}>0 .
\end{gathered}
$$

Since $(n-1)$ is negative and the fraction $m /(n-1)$ is positive, $m$ must be negative. Negative values of $m$ (relative price sensitization) therefore result in instability of time allocation to $X$ and $Y$. On the other hand, positive values of $m$ (relative price habituation) produce values of $r$ that are less than unity. Therefore, relative price habituation results in stable consumption allocations.

Note that, even with negative values of $m$, harmful addiction does not automatically follow. If the initial value of $X$ is less than that of $Y$, and $m$ is negative, all consumption shifts to $Y$. By assumption, $Y$ is price sensitized. High levels of many pricesensitized activities, such as listening to classical music, reading Trollope novels, and socializing, are not normally harmful. But even these activities may become harmful if done to excess, and some such activities (television watching or Web surfing) are considered addictions at high levels.

On the other hand, if $m$ is negative and the initial value of $X$ is greater than that of $Y$, all consumption shifts to $X$. By assumption, $X$ is price habituated. High levels of at least some price-habituated activities, such as drinking alcohol, sniffing cocaine, and smoking cigarettes, are indeed normally harmful.

(Manuscript received February 4, 1997; revision accepted for publication July 9, 1997.) 